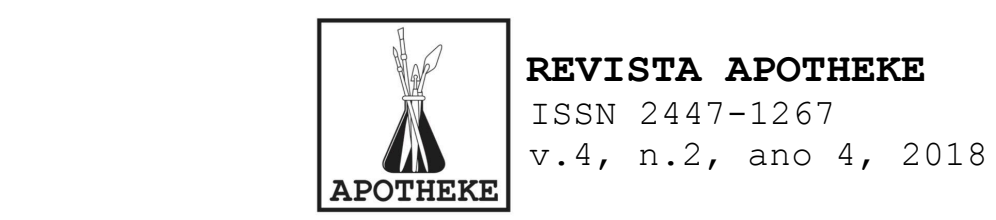

\title{
Pescador de possíveis a montagem como possibilidade de um trabalho com imagens
}

\author{
Wolney Fernandes de Oliveira (PUC Goiás)
}

\begin{abstract}
RESUMO
Ao mapear os fazeres e os saberes contidos nas minhas práticas de artista tenho entendido a montagem como elemento importante no processo de criação de uma colagem e, consequentemente, no trabalho com imagens. Orientado pela vontade de efetivar um pensamento conectado com minha experiência, neste texto procuro colocar atenção nos princípios que a montagem de uma colagem possibilita, aproximando-a da noção de atlas de imagens desenvolvida por Aby Warburg onde me é oferecida uma configuração visual de pensamentos por onde acontece o intercâmbio, a circulação e a sobrevivência (DIDI-HUBERMAN, 2013) das imagens.
\end{abstract}

PALAVRAS-CHAVE: montagem. Colagem. atlas. práticas de artista.

\section{ABSTRACT}

By mapping the actions and knowledge contained in my artist practices I have understood the montage as an important element in the process of creating a collage and, consequently, in the work with images. Guided by the will to effect a thought connected with my experience, in this text I try to pay attention to the principles that the montage of a collage makes possible, approaching the notion of atlas of images developed by Aby Warburg where I am offered a visual configuration of thoughts by where the exchange, circulation and survival (DIDI-HUBERMAN, 2013) of the images.

KEYWORDS: montage. collage. atlas. artist practices.

A experiência que dá corpo a este texto teve início durante meu doutoramento - de 2012 a 2016 - no Programa de Pós-Graduação em Arte e Cultura Visual pela Universidade Federal de Goiás. Mais especificamente na segunda metade deste período quando comecei a produzir imagens utilizando a técnica da colagem e propondo uma maior circulação destes trabalhos. Isso coincidiu com meus estudos sobre o atlas de imagens atribuída à ideia de Mnemosyne desenvolvida por Aby Warburg ${ }^{1}$ e me levou a relacionar essas duas práticas.

\footnotetext{
Abraham Moritz Warburg mais conhecido como Aby Warburg (Hamburgo, 13 de junho de 1866 - 26 de outubro, 1929) foi um historiador da arte alemão, célebre por seus estudos sobre o ressurgimento do paganismo no renascimento italiano. Ficou conhecido também pela Biblioteca referencial que levava seu nome, e que reunia uma grande coleção sobre ciências humanas e que, ao ser transferida para Londres em 1933, tornou-se a base para a constituição do Instituto Warburg. (Fonte: http://pt.wikipedia.org/wiki/Aby_Warburg (acesso em 05/06/2018).
} 


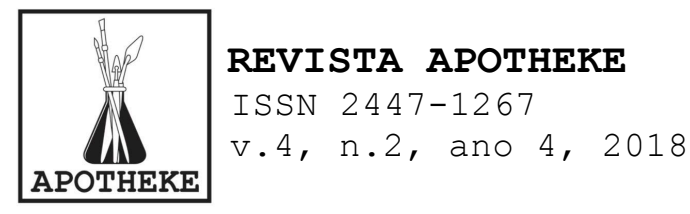

Através dos meus fazeres de artista tenho me levantado uma série de questionamentos e delineado algumas convicções na tentativa de me conectar a um persistente desejo de aprendizagem com aquilo que me mobiliza. No encalço dessa conexão, tenho me perguntado: Como mapear os fazeres-saberes contidos nas minhas práticas? Como reconhecê-los como ferramentas para investigações cognitivas? Como organizar minhas experiências para tirar delas interações e movimentações capazes de ampliar meu campo de trabalho?

Plantadas no período de desenvolvimento da minha tese ${ }^{2}$, estas indagações foram revolvidas intensamente nos últimos anos em tentativas de articulá-las junto à minha experiência como artista. Faço isso, orientado pela vontade de efetivar um pensamento das artes que se cumpre como "um modo de articulação entre maneiras de fazer, formas de visibilidade dessas maneiras de fazer e modos de pensabilidade de suas relações" (RANCIÉRE, 2009, p. 13). Faço também para estabelecer um diálogo com meus próprios enfrentamentos, com o que me inquieta e mobiliza, no entendimento de que essa movimentação, ao mesmo tempo que provoca um olhar sobre mim mesmo, também me conecta a um processo coletivo. Além disso, ainda carrego a esperança de que, através dessa relação dialógica, eu consiga imprimir certa fluidez em minhas práticas acadêmicas.

\section{Como produzir singularidades?}

Minha trajetória como artista sempre operou em diferentes modalidades expressivas, mas desde 2013 tenho voltado meus fazeres e colocado sentido(s) na prática da colagem. Algumas observações realizadas em torno deste fazer é o que dá

2 OLIVEIRA, W. F. de. Fazeres-saberes cartografados à partir da memória do meu avô. Goiânia: tese de doutorado em Arte e Cultura Visual. Faculdade de Artes Visuais/UFG, 2016. 


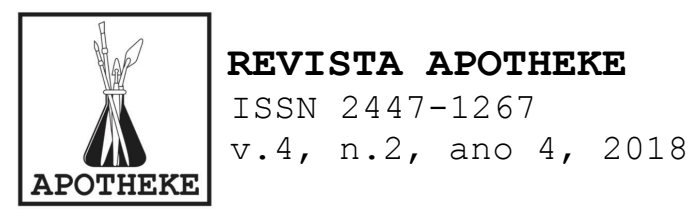

sustentação a este texto, pois tenho pensando a colagem como um território capaz de abarcar uma movimentação ziguezagueante em torno de experiências com imagens. Uma transposição minimamente ordenada do modo como construo meu pensamento, pois é no fazer que o pensamento se constitui, institui e se materializa, onde uma forma chama outra, seja pela semelhança, seja pelo contraste.

Segundo Renato Cohen, "a colagem seria a justaposição de imagens não originalmente próximas, obtidas através da seleção e picotagem de imagens encontradas, ao acaso, em diversas fontes" (COHEN, 1989, p. 60, grifo meu). Espécie de depósito coletivo de informação, na colagem todas as imagens se equivalem indistintamente. Qualquer tema pode ser combinado e atado a outro, como faz o "Pescador de Possíveis" na imagem de minha autoria que apresento abaixo (Figura 1). Nela, vemos uma pessoa que tenta estabelecer uma conexão entre dois elementos muito distintos em natureza e localização (uma lua e um peixe). As linhas das paisagens que dividem a imagem são igualmente distintas. Acima, temos traços sinuosos e abaixo, movimentos mais retilíneos que reforçam o contraste de cada um dos elementos que estão sendo atados. 


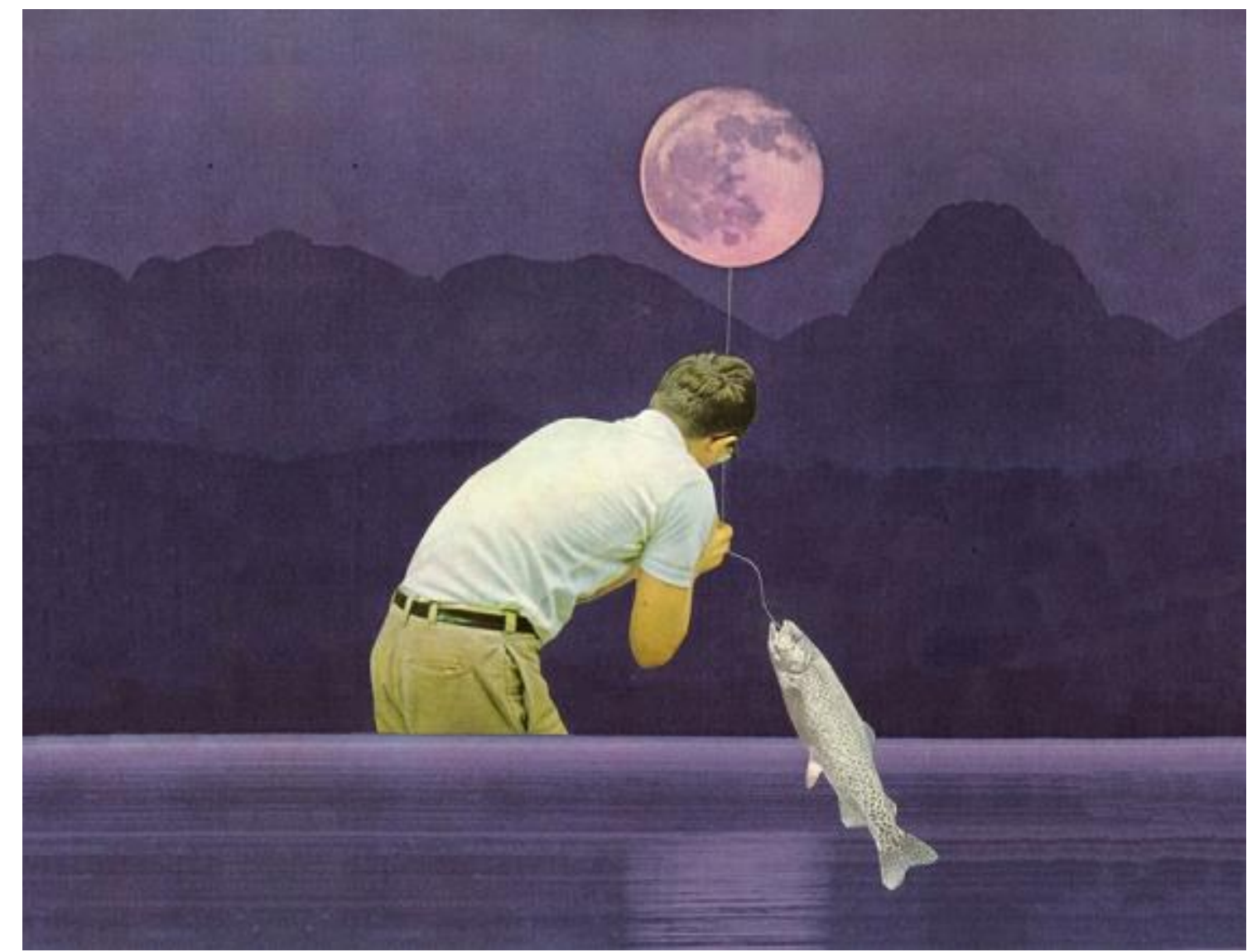

Figura 1: Pescador de Possíveis. Colagem analógica, 2013. Acervo do autor.

A cena que a colagem acima retrata sugere potências investigativas para se pensar uma movimentação e uma conexão entre imagens. Desse modo, coloco minha atenção nos princípios que a montagem de uma colagem possibilita, aproximando-a da noção de atlas de imagens atribuída à ideia de Mnemosyne ${ }^{3}$ (WARBURG, 2015) desenvolvida por Aby Warburg onde me é oferecida, não a ilustração e sim uma a configuração visual de pensamentos por onde acontece o intercâmbio, a circulação e a sobrevivência (DIDI-HUBERMAN, 2013) das imagens.

Sugerido pela figura central da colagem, o movimento de debruçar-se sobre as coisas realça também a ideia do corpo

3 o Bilderatlas Mnemosyne (Atlas de Imagens Mnemosine), em seu nome, homenageia a musa grega da memória, Mnemosine. Era o projeto mais ambicioso de Warburg, que pretendia estabelecer "cadeias de transporte de imagens", linhas de transmissão de características visuais através dos tempos, que carregariam consigo o pathos, emoções básicas engendradas no nascimento da civilização ocidental, nessas imagens. (Fonte: http://pt.wikipedia.org/wiki/Aby_Warburg (acesso em 05/06/2018). 


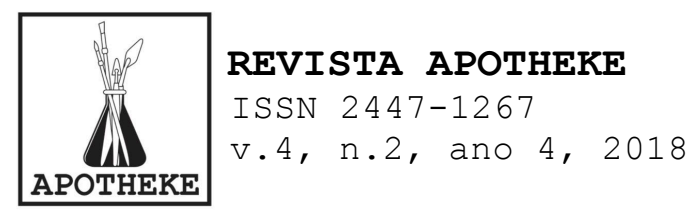

perceptivo que não só está no espaço, mas pertence a ele se valendo da capacidade de não apenas estar entre as coisas, mas de tecer relações entre elas (DIDI-HUBMERMAN, 2015). Elementos diversos coletados e apreendidos das fontes mais aleatórias e que são incorporados, de fato, a nossos hábitos, prazeres e opiniões. Tenho entendido essa habilidade como aquilo que é capaz de produzir um conhecimento autêntico que é definido não pelo número ou tipo de informações armazenadas, mas sim pelo fato de conseguir tecer relações entre estas informações no momento em que se precisa delas.

Em um mundo bombardeado por imagens, essa capacidade de associação expõe uma constante investigação, pois desconsidera hierarquias e remixa olhares. No caso da colagem, mistura recortes de jornal, fotografias de satélite, ilustrações de científicas, referências da história da arte e toda sorte de impressos ${ }^{4}$. O repertório de imagens prontas é entrecruzado a partir de novas combinações que atualizam e reposicionam seus significados. São multiplicidades que variam continuamente, e por isso não se assemelham a universalidades, determinismos ou representações.

Aceitar a multiplicidade de cada sentido sugerido pelas imagens contribui para a construção da diferença como tal, sem submetê-la a nenhuma forma de representação que a reconduza ao mesmo. Não há matéria fixa e imutável, pois a dialética matéria-forma é substituída pela conexão dinâmica do suporte numa busca incessante por singularidades (DELEUZE, 1998). Esse pensamento se conecta com a premissa de que a construção de objetos complexos e singulares depende de pressupostos complexos e singulares assumidos pelos sujeitos que os constroem, e não dos objetos em si.

Mesmo tendo uma intencionalidade, ao lidar com os recortes de imagens e seus inúmeros prolongamentos, ora

\footnotetext{
${ }^{4}$ Procedimentos vinculados à colagem analógica. A colagem digital lida com operações distintas.
} 


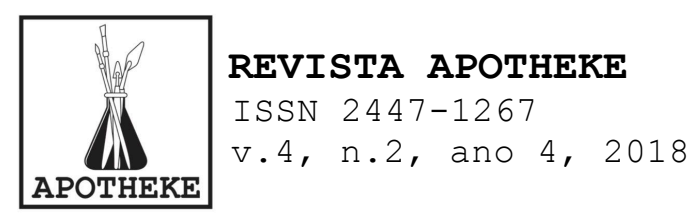

enfatizando, ora excluindo algumas combinações, ao produzir uma colagem, entendo que estou construindo uma narrativa em torno de outras narrativas. Portanto, além de entendê-la como uma construção parcial, marcada por um determinado ponto de vista, é visível que nunca será possível abarcar e apreender sua totalidade, mas apenas apresentar uma demarcação semântica dentre tantas possíveis que as imagens carregam.

\section{A montagem como possibilidade de investigação}

A elaboração de uma colagem analógica pressupõe a utilização de determinados materiais e também de certos movimentos cumpridos ao longo do procedimento. Dentro dos processos criativos vinculados às minhas práticas como colagista eu costumo destacar três movimentos fundamentais, a saber:

a) A busca por imagens em fontes variadas.

b) A montagem das partes encontradas nestas fontes.

c) A fixação destas partes em uma composição.

Pelas entrelinhas dessas operações é possível cruzar ideias, percepções e práticas acumuladas em torno de uma experiência. A ideia deste texto é fazer um recorte no item "b" na tentativa de fundamentar o movimento da montagem como uma ação capaz de reconfigurar um percurso em um ato de enunciação. Ao escolher e recortar as partes de uma colagem, antes de fixar estas partes recortadas, há um movimento combinatório que permite misturar estilos variados, épocas distintas, diferentes categorias e significações. Fernando Fuão chama de "encontro" essa relação entre imagens.

\footnotetext{
O encontro na collage se estabelece no intervalo significante entre os limites posteriores ao recorte e anteriores à colagem, quando as figuras são testadas em suas aproximações e significados, antes que a cola 'asfixe' definitivamente sobre o suporte-papel. É o instante em que o movimento da produção se acelera, e as figuras já recortadas agitam-se e dançam totalmente livres e sem compromisso, umas sobre as outras. Umas em buscas das outras. (FŨ̃O, 2011, p. 75)
} 


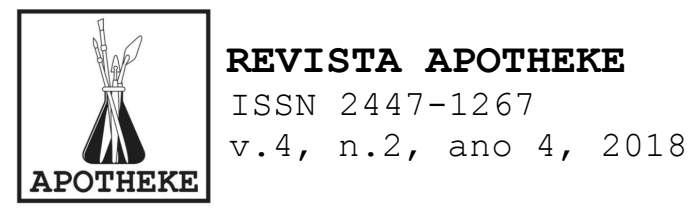

Esse movimento de busca e de encontro equivale a uma mecânica de articulação de imagens que são reutilizadas em uma dinâmica capaz de realçar sentidos cambiantes, movediços e transitórios. É um descobrimento por onde o pensamento se transforma caracterizando um estado aberto, perceptivo e receptivo. Cada fragmento de imagem, portanto, torna-se um memorando de ações desejadas, planejadas, abandonadas, reorientadas numa rede de afinidades e relacionamentos das imagens entre si, com permutação de suas configurações iniciais.

A montagem, portanto, traz subsídios para pensar a rede de relações e seus processos a partir da imagem viva, que é imagem e que sempre resulta num ponto de encontro dinâmico e heterogêneo quando nos propomos a movimentá-la. Dessa forma, o processo pode respeitar sua multiplicidade, além de outorgar legibilidade às relações postas em evidência.

A ideia de montagem e movimentação de imagens constitui um work in progress de fragmentos imagéticos em agenciamentos concebidos para expor conjuntamente e visualmente, as imbricações do trabalho com imagens como um ato interpretativo. O desejo de estar diante dessas imagens (Figura 2) enredadas à partir de um outro lugar também aspiram efetivamente "uma desmontagem do continuum figurativo, por fusões de detalhes entrecortados e por remontagem desse material em ritmos visuais inéditos." (DIDI-HUBERMAN, 2013, p. $448)$. 

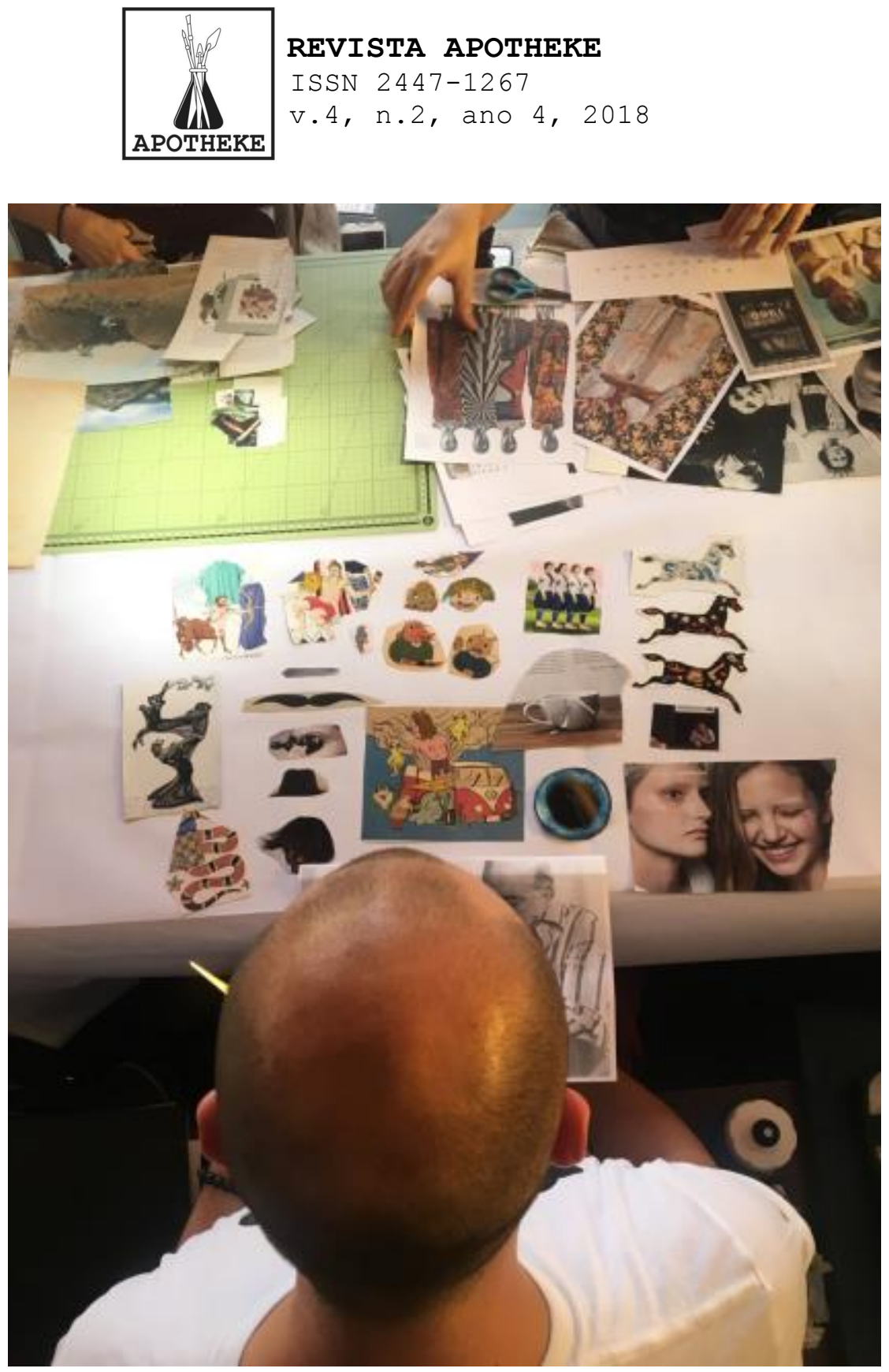

Figura 2: Movimento dos fragmentos de imagens. Acervo do autor.

Há também, neste movimento, a expectativa de desenvolver outra visão daquilo que é experimentado considerando o abandono da representação unívoca da realidade na tentativa de proporcionar sentidos alternativos, de estender e/ou comprimir verdades dando a elas um caráter flexível, moldável segundo uma determinada percepção. Pela combinação de imagens e agrupamento de fragmentos distintos há a expectativa de que os detalhes possam trazer à tona elaborações que, à priori, não estavam tão evidentes. Para DIDI-HUBERMAN, o detalhe precisa ser compreendido a partir de seus efeitos de intromissão ou exceção, conforme esclarece: 


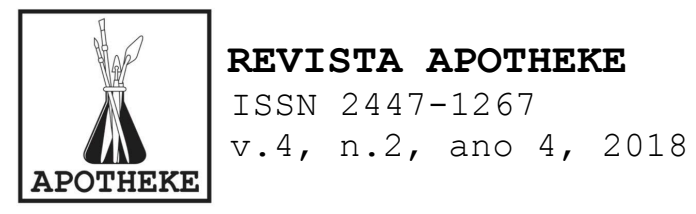

De que é feita uma montagem? quais são seus elementos?
(...) Detalhes: pequenas coisas não percebidas, como os
temas discretos perdidos no claro-escuro de um afresco, o
verso de uma medalha desconhecida ou a modesta base de
estátua que percebemos, aqui e ali, ao longo do atlas
warburguiano. (DIDI-HUBERAN, $2013, \mathrm{p} .410$ ).

Dentro desse processo entram em jogo outros elementos como a observação do singular, do idiossincrático, bem como sua capacidade de ordenar os fragmentos numa sequência narrativa, cuja formulação se dá pela intenção, mas também pelo faro, pelo golpe de vista, pela intuição. Essa constante reordenação dos fragmentos sugere uma espécie de mapeamento compositivo, um esquema indiciário ou mesmo um atlas.

\section{Atlas como lugar de múltiplas migrações}

Por definição, atlas é um conjunto de mapas, porém, o termo também se aplica a um conjunto de dados sobre determinado assunto, sistematicamente organizados e servindo de referência para a construção de informações de acordo com a necessidade do usuário. A palavra atlas é inspirada na mitologia grega, que narra a história do titã Atlas que tomou a frente das batalhas de cronos e dos Titãs contra os deuses do Olimpo, deixando Zeus furioso. Como castigo, foi obrigado a carregar o mundo nas costas, para sempre.

Por causa disso, a palavra atlas está quase sempre associada a algum tipo de apoio: na coluna vertebral, por exemplo, a primeira vértebra se chama atlóide, porque sustenta a cabeça. Atlas também pode designar algo que serve como coluna de sustentação em construções. Um atlas funciona como apoio e, portanto, ter à mão um atlas é ter algumas informações. Para Didi-Huberman:

Fazer um atlas é reconfigurar o espaço, redistribuí-lo, desorientá-lo enfim: deslocá-lo aí onde pensávamos que era contínuo, reuni-lo ali onde supúnhamos que havia fronteiras. Arthur Rimbaud recortou um dia um atlas 


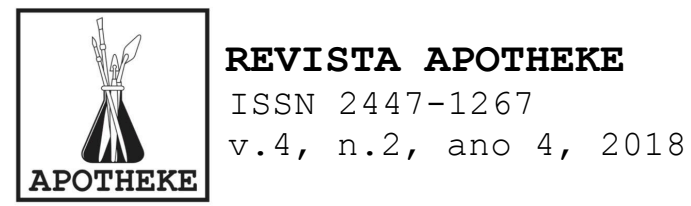

geográfico para consignar a sua iconografia pessoal com os pedaços obtidos. Aby Warburg já tinha entendido que qualquer imagem - qualquer produção de cultura em geral é um encontro de múltiplas migrações. São numerosos os artistas contemporâneos que não se conformam apenas com uma paisagem para contar-nos a história de um país: são a razão pela qual coexistem, numa mesma superfície - ou lâmina de atlas - diferentes formas para representar o espaço. (DIDI-HUBERMAN, 2011, p. 88). ${ }^{5}$

Sustentado por essas associações, durante a procura de um modo de inserção e recombinação nos inumeráveis fluxos contidos nos recortes das imagens, surgem algumas questões: Como esses espaços entre imagens podem revelar experiências singulares? Quais são suas maneiras de fazer pensar? No emaranhado de referências, camadas de informação aparecem justapostas e sobrepostas onde visualidade e tateabilidade se afirmam mutuamente, operando numa esfera que, a meu ver, em muito se aproxima das formulações de Didi-Huberman sobre a montagem de imagens de arquivo. Segundo o autor,

\begin{abstract}
Quando colocamos diferentes imagens - ou diferentes objetos, como as cartas de um baralho, por exemplo - em uma mesa, temos uma constante liberdade para modificar sua configuração. Podemos fazer pilhas, constelações. Podemos descobrir novas analogias, novos trajetos de pensamento. Ao modificar a ordem, fazemos com que as imagens tomem uma posição. Uma mesa não se usa nem para estabelecer uma classificação definitiva, nem um inventário exaustivo, nem para catalogar de uma vez por todas - como em um dicionário, um arquivo ou uma enciclopédia -, mas sim para recolher segmentos, traços da fragmentação do mundo, respeitar sua multiplicidade, sua heterogeneidade. E para outorgar legibilidade às relações postas em evidência (DIDI-HUBERMAN, 2010. Disponível em <http://www.culturaebarbarie.org/ sopro/outros/atlas.html> Acesso em 20/07/2015).
\end{abstract}

Os percursos elaborados e apontados em um processo de montagem encontram respaldo no intercâmbio e circulação de imagens e seus sentidos cambiantes. A busca por uma forma autônoma e original é, portanto, substituída pela incursão em

5 Conferência de Georges Didi-Huberman realizada no seminário de antropologia do visual da EHESS de Paris (INHA, auditorium, 2 rue Vivienne 75002, Paris. Em 2010/2011). Ver Augé; Didi-Huberman; Eco, 2011, p. 88. 


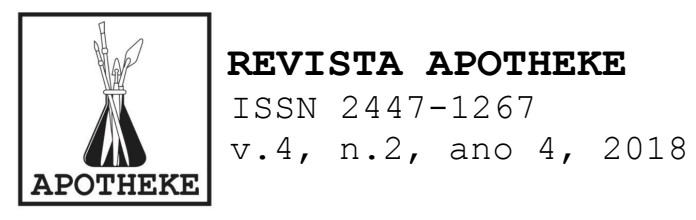

uma rede de formas já produzidas, conferindo ao artista a função de operador de significados na intenção de produzir, antes de mais nada, percursos originais por meio de uma rede semântica.

A articulação da diferença possibilita o conhecimento daquilo que se mantém parcialmente exposto e por consequência, daquilo que se mantém parcialmente invisível. Nesse aspecto, os processos de montagem apontados por Didi-Huberman, são capazes de gerar visibilidade dando forma ao conhecer, mesmo que algo escape dessa visualização, mesmo que algo permaneça "inacessível como um todo" (DIDI-HUBERMAN, 2012, 176).

A montagem nos dá a ver, a pensar, a conhecer, a imaginar, a evocar... Ela seria a arte de produzir uma forma que pensa, pois procede e atua de forma dialética. No entanto, não necessariamente tal processo absorve as diferenças chegando a uma síntese, mas, ao contrário, pode fazê-las emergir, criando o choque, a tensão, a turbulência, a suspensão. Diferentemente da contemplação, tanto a disposição das imagens quanto o conteúdo das imagens, propõem outros tipos de associações através de seus movimentos como podemos observar na Figura 3. Nela, a posição da cobra menor pode compor duas narrativas dependendo da posição escolhida em relação às outras partes. 

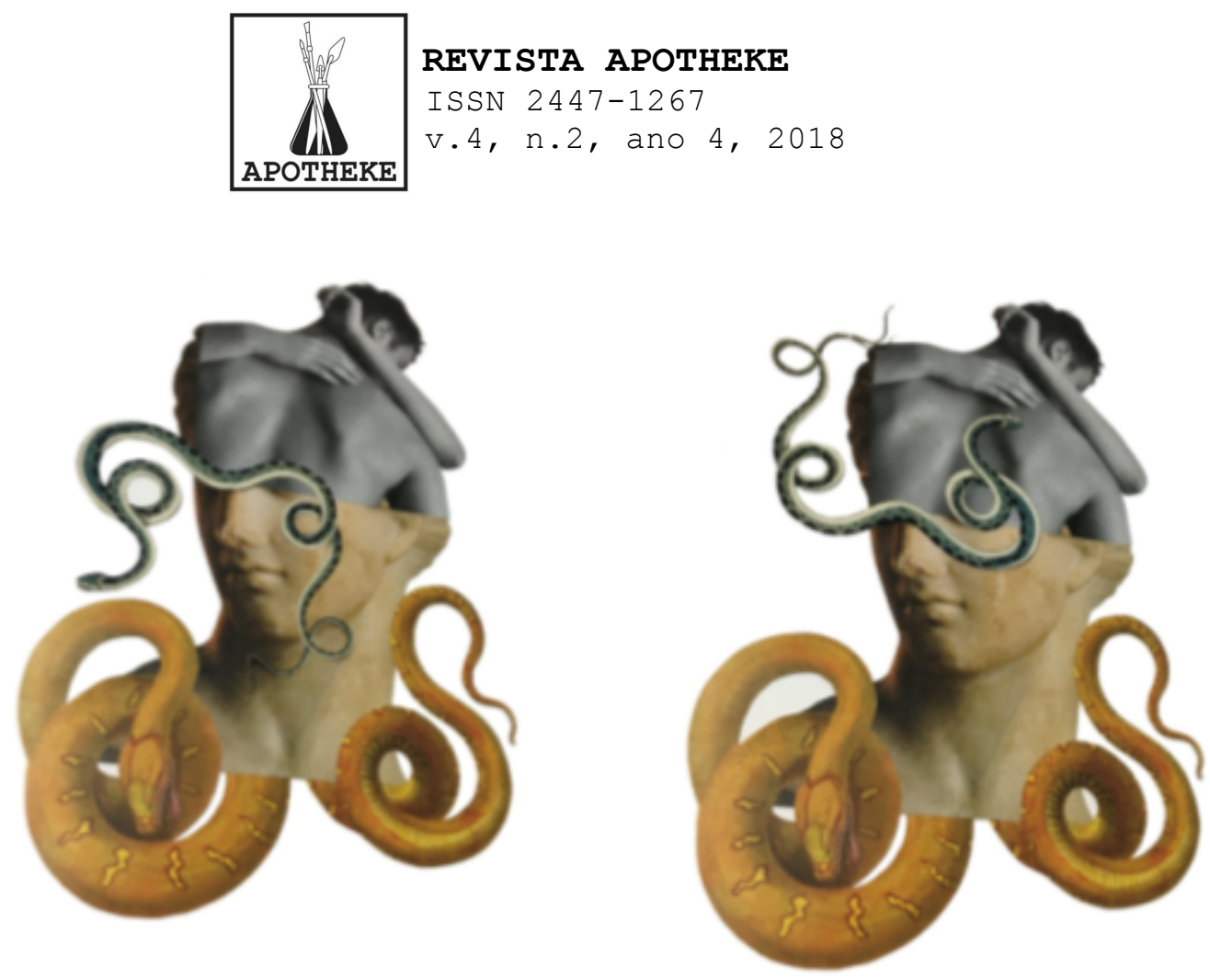

Figura 3: Perfume de mármore. Colagem analógica. 2017. Acervo do autor.

A montagem é também evocada e mencionada por Walter Benjamin como método de trabalho para a criação de seu Das Passagen-Werk. 6 Ao apresentá-la, especifica-a como "montagem literária", justificando-a ao assumir que nada teria a dizer, apenas a mostrar. Dessa forma não tomaria para si coisas valiosas, tampouco se apropriaria de formulações espirituosas. Sua pretensão não era a de inventariar "farrapos" ou "resíduos", mas "fazer-lhes justiça da única maneira possível: utilizando-os" (BENJAMIN, 2009, p. 502). Para Benjamin, dentro de uma montagem, a imagem irromperia como um clarão - preciso, incisivo, mas efêmero - resultante da colisão do ocorrido com - agora, num lampejo, formando uma noção de imagem dialética.

A imagem como o lugar de um processo vivo, também participa de um sistema de pensamento (SAMAIN, 2012). O método benjaminiano de montagem se assemelha muito ao de Aby Warburg. A perspectiva do Atlas Mnemosyne, último e inacabado projeto de Warburg se refere a um conjunto de imagens que reunia em

\footnotetext{
6 Das Passagen-Werk ou Trabalho das passagens é um conjunto de textos que se relacionam a um grande projeto: um livro sobre a cidade de Paris no século XIX. Benjamin retoma nele o velho motivo do "livro do mundo" e emprega-o em sua "leitura" da cidade de Paris do século XIX. Em 2009, este trabalho foi publicado pela editora da UFMG.
} 


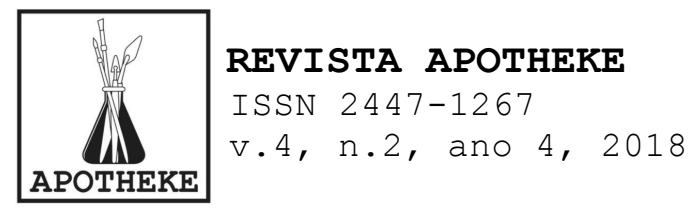

diferentes papéis, reproduções dos seus temas favoritos da história da arte, mas também imagens publicitárias, selos, fotografias de imprensa... Uma constelação feita a partir de aproximações intuitivas entre imagens, textos e símbolos em uma espécie de atlas complementar de uma memória. Como uma espécie de enciclopédia de movimentos constantes,

\begin{abstract}
Mnemosyne é um objeto intempestivo, por se atrever, na era do positivismo e da história triunfal, a funcionar como um quebra-cabeça ou um jogo de cartas de tarô desproporcionais (configuração sem limites, número infinitamente variável de cartas por jogar). Nele, as diferenças nunca são reabsorvidas numa entidade superior: como no mundo fluido da "participação", elas são animadas por suas ligações, descobertas-através de uma experimentação sempre renovada pelo cartomante desse jogo com o tempo. (DIDI-HUBERMAN, 2013, p.406).
\end{abstract}

As imagens vistas por Warburg, em seu projeto de montagem, aparecem em uma disposição fotográfica que forma quadros com fotografias no sentido combinatório. O autor colocaria assim em questão a idéia de uma memória viva ao criar um conjunto de imagens relacionando-as entre si e tornando presente fendas temporais na disposição das fotos e em suas relações diversas (Figura 4). Como constelações, elas adquirem caráter permutáveis em um incessante deslocamento combinatório, questionando um tipo de narrativa única, construindo um pensamento movente, irredutível à ordem do discurso. 

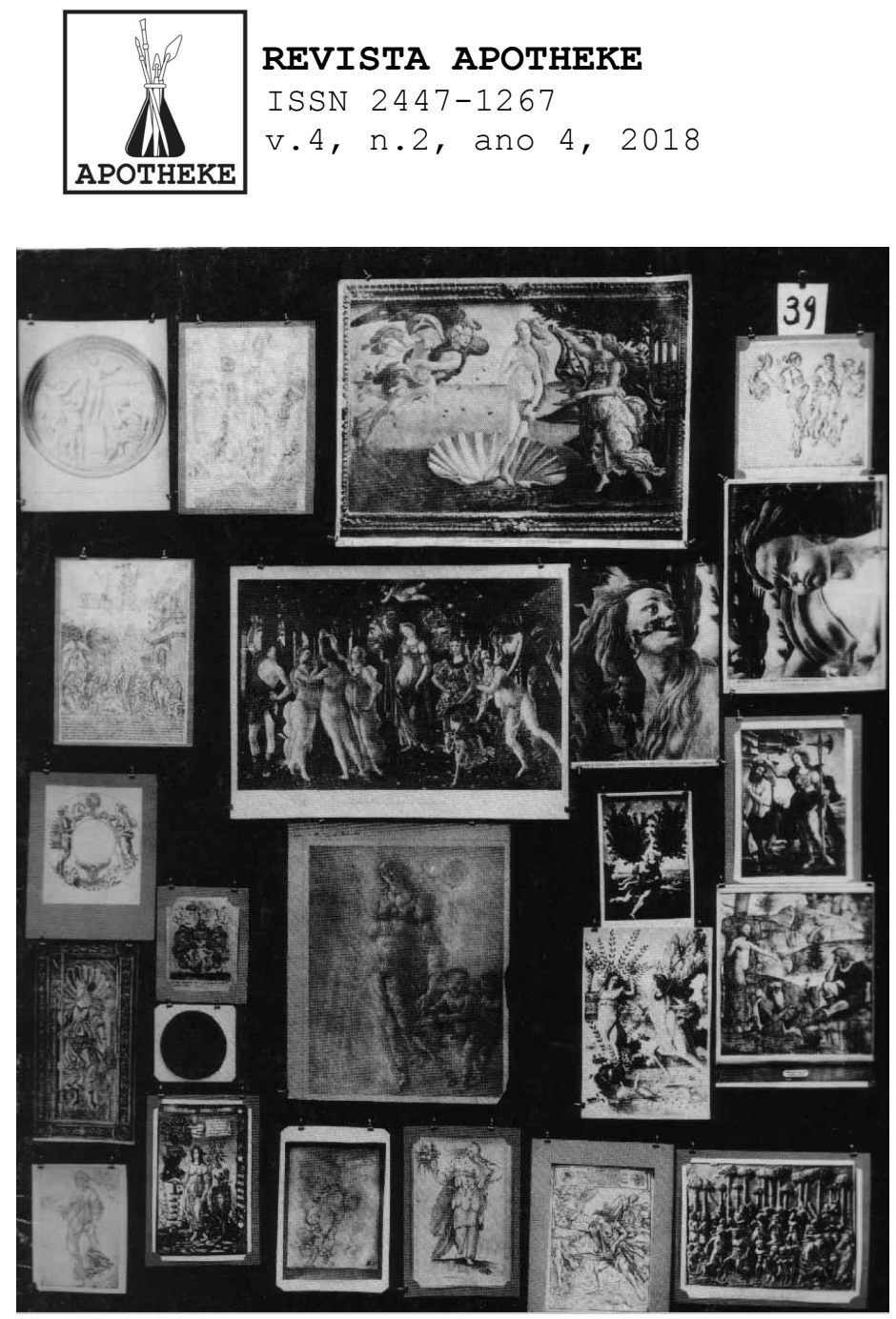

Figura 4: Parte do painel de Aby Warburg.

Imagem capturada em <http://www.aisthesisonline.it/2010/2-2010/i-warburg/> Acesso em 10/06/2018.

Em seus tempos diversos, esse movimento de elaboração visual do pensamento descortina diferentes frequências, ritmos e colisões. Seus espaços vazios provocam organizações de imagens heterogêneas e anacrônicas adquirindo em Mnemosyne força de memórias justapostas, em que nada está situado antes ou depois. É dessa maneira que aponta um modelo de tempo próprio das imagens e se concentra no processo de produção de imagens e ideias como algo que não se restringe apenas à uma elaboração mental.

Na elaboração de uma colagem, ao propor a interação entre imagens díspares, tanto na forma quanto no conteúdo, essa ideia de aproximação permite reunir visualidades afastadas no tempo e no espaço. Dessa forma, a dinâmica do atlas aponta percursos que não são lineares e determinados. "São caminhos e 

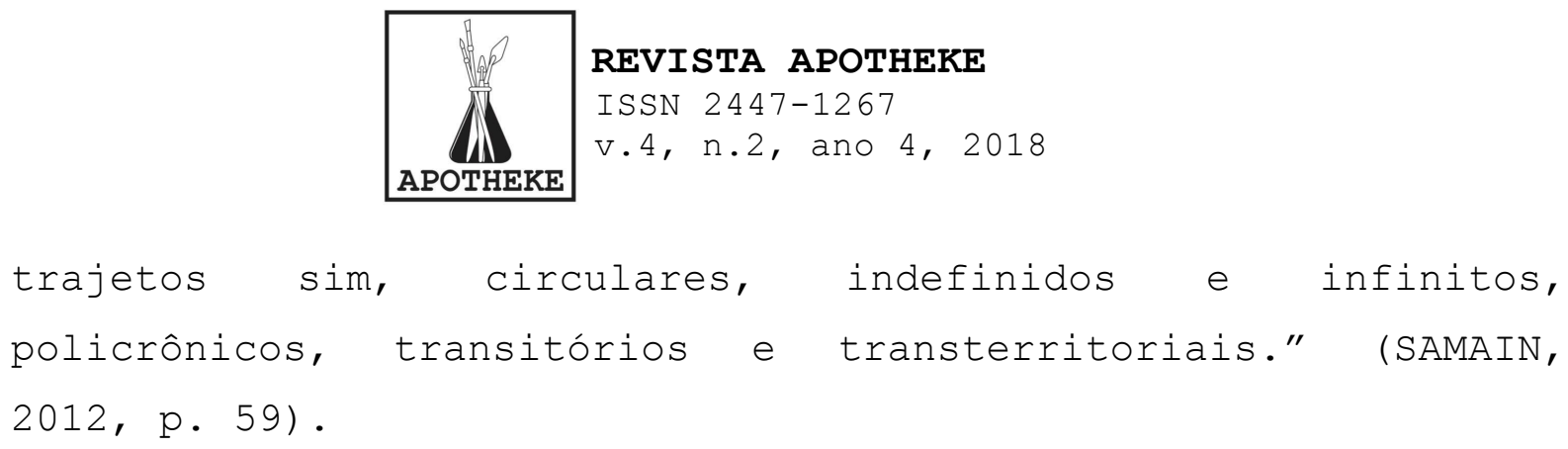

A ideia de um atlas, no pensamento de Warburg revelou-se uma forma que, a seu ver, não era apenas um "resumo em imagens", mas um pensamento por imagens. Não apenas um "lembrete", mas uma memória no trabalho. Em outras palavras, a memória como tal, a memória "viva". (DIDIHUBERMAN, 2013, p. 383).

Como sugere Didi-Huberman, a imagem é feita de sentidos, mas não só: "uma das grandes forças da imagem é a de produzir ao mesmo tempo sintoma (ruptura dentro do saber) e conhecimento (ruptura dentro do caos)" (DIDI-HUBERMAN, 2013, p. 33). Dentro do processo de significação das imagens coexiste um resultado e também uma perturbação.

A cadência desse movimento tensivo e anacrônico também sugere que se entenda a montagem como um movimento criativo. A criação praticada é apresentada como um processo contínuo de interconexões instáveis, mas capazes de gerar nós de interação e cuja variabilidade obedece a alguns princípios direcionadores, mas não se prendem a eles. Além disso, o trabalho de movimentar partes envolve a percepção de diferentes modos de se organizar as tramas de um pensamento que se constrói também pelo movimento das mãos. Um "gesto inacabado" (SALLES, 2006) com tendências incertas e indeterminadas, mas capazes de levar quem o pratica a buscar percursos de experimentação.

\section{Movimento entre imagem e pensamento}

Há uma complexa trama que envolve a relação entre imagem e pensamento, que é desencadeada pela proposta do movimento entre elas. A profunda conjunção entre imagens e movimento é capaz de alterar os contextos que elas revelam. Como já visto anteriormente, a colagem "O Pescador de Possíveis" (Figura 1) 


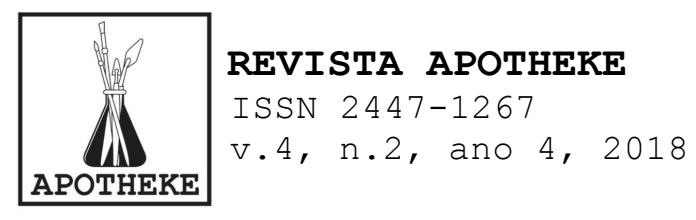

sugere um movimento duplamente significativo: do artista que se debruça em busca de afinar suas ideias e de imagens transitórias capazes de promover diversas aproximações e reaparições. Michaud aponta indícios da importância do movimento dentro desse processo, assegurando que essa ação se refere à elaboração de um pensamento, "de uma ideia que se baseia no movimento". (MICHAUD, 2013, p. 10).

A importância dessa movimentação ultrapassaria a simples alteração nos modos de se perceber a imagem. Para esse autor, - movimento "faz do desfile de imagens um instrumento de análise" (idem, p. 10) permitindo que as ideias escapem à objetividade informacional e envolvam sua externalização, configurando-as de forma que possam ser comparadas, classificadas, combinadas, avaliadas e compartilhadas.

Sendo assim, o conhecimento estaria ligado intimamente a esta movimentação cuja origem e fundamento é a própria ação e não um pensar que a antecede. Ou seja, o gesto que caracteriza a montagem está intrinsecamente atrelado à um fazer que é pensar. O impacto desta postura alude a possibilidade de uma montagem capaz de propor singularidades dentro da uma experiência de trabalho com imagens. Colocar em movimento, em vários aspectos, contraria o linear, o já reconhecido e estabelecido e pode funcionar como ocasião oportuna para rever narrativas e seus adensamentos percebendo como elas alinham-se à uma série de impulsos e colisões vitais ladeadas por procedimentos contaminantes e liminares.

Se vistas como organismos vivos, as imagens e sua constante movimentação - ora esquecida, ora redescoberta atravessam períodos de latência e de crise, repete-se e metamorfoseia-se (WARBURG, 2015). À semelhança de Mnemosyne que foi definido por Warburg como uma "história de fantasmas para adultos" (DIDI-HUBERMAN, 2013, p. 88), as possibilidades apresentadas pelo processo de montagem desdobram vias complexas e difusas, que assustam, mas também nos colocam a 


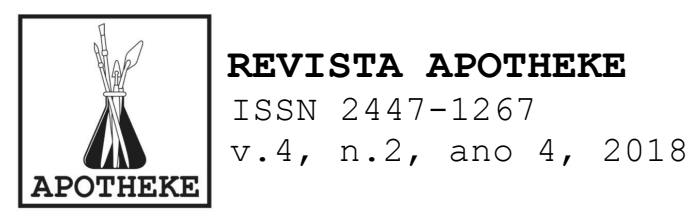

exigência de criarmos um corpo movente, em nossa existência, em nosso modo de sentir, de pensar e de agir.

\section{REFERÊNCIAS}

AUGÉ, M.; DIDI-HUBERMAN, G.; ECO, U. L'Expérience des Images. Brysur Marne: Editons INA, 2011.

BENJAMIN, W. Passagens. Belo Horizonte: Editora UFMG; São Paulo: Imprensa Oficial do Estado de São Paulo, 2009.

COHEN, R. Performance como linguagem: criação de um tempo-espaço de experimentação. São Paulo: Perspectiva, 1989.

DELEUZE, G. Diferença e Repetição. Rio de Janeiro: Graal, 1988.

DIDI-HUBERMAN, G. Atlas - como levar o mundo nas costas? In: Sopro: panfleto político cultural, n. 41. Florianópolis: Ed.Cultura e Barbárie. 2010. Disponível em <http://www.culturaebarbarie.org/sopro/outros/atlas.html> Acesso em $20 / 07 / 2015$.

DIDI-HUBERMAN, G. Imagens Apesar de Tudo. Lisboa: KKYM, 2012.

DIDI-HUBERMAN, G. A imagem sobrevivente: história da arte e tempo dos fantasmas segundo Aby Warburg. Rio de Janeiro: Contraponto, 2013.

DIDI-HUBERMAN, G. Pensar debruçado. Lisboa: KKYM, 2015.

FUÃO, F. F. A collage como trajetória amorosa. Porto Alegre: Editora UFRGS, 2011 .

MICHAUD, P. A. Aby Warburg e a imagem em movimento. Rio de Janeiro: Contraponto, 2013.

RANCIÈRE, J. A partilha do sensível: estética e política. São Paulo: editora 34, 2009 .

SALLES, C. A. Redes de Criação: construção da obra de arte. São Paulo: Horizonte, 2006.

SAMAIN E. (Org.). Como pensam as imagens. Campinas/SP: Editora da Unicamp, 2012.

WARBURG, A. Histórias de fantasma para gente grande: escritos, esboços e conferências. São Paulo: Companhia das Letras, 2015. 